\title{
Erratum to: On a New Type of Hyperstability for Radical Cubic Functional Equation in Non-Archimedean Metric Spaces
}

\author{
Iz-iddine EL-Fassi
}

\section{Erratum to: Results Math 72 (2017), 991-1005 \\ DOI 10.1007/s00025-017-0716-2}

In our original paper (DOI 10.1007/s00025-017-0716-2), we study the generalised hyperstability results for Radical cubic functional equation in nonArchimedean metric spaces. In the present paper, I need to carry out the following corrections:

- In Theorem 3.1 and Corollary 3.1, $\lim _{n \rightarrow \infty} s_{1}(n) s_{2}(-n)=0$ must be

$$
\lim _{n \rightarrow \infty} s_{1}(n) s_{2}(1-n)=0 .
$$

- Above Remark 1 by two lines, $\lim _{m \rightarrow \infty} s_{1}(m) s_{2}(-m)=0$ must be

$$
\lim _{m \rightarrow \infty} s_{1}(m) s_{2}(1-m)=0 \text {. }
$$

Iz-iddine EL-Fassi

Department of Mathematics, Faculty of Sciences

Ibn Tofail University

BP 133, Kenitra

Morocco

e-mail: izidd-math@hotmail.fr;

izelfassi.math@gmail.com

The online version of the original article can be found under doi:10.1007/s00025-017-0716-2. 